\title{
Digital Financial Decision With A View of Neuroplasticity / Neurofinancy / Neural Networks
}

https://doi.org/10.21272/fmir.2(4).82-91.2018

\section{Ana Njegovanović}

Master of Economics, Lecturer at Faculty of Biotechnology in Zagreb; Faculty of Economics and Tourism, University of J. Dobrila in Pula, Croatia

\begin{abstract}
This paper provides a decision-making debate that supports the digital system as well as some issues related to digital finance, the future of financial decision-making is linked to artificial intelligence and the need for new knowledge by understanding the financial complexity of how our brain processes financial decisionmaking and neural networks with an integrative framework that brings neuroplasticity outcomes from neuroscience perspective.

In pursuit of the goal, we use scientific literature that links financial decision-making through scientific disciplines and technology, thus contributing to linking science disciplines and pointing to the need for continuous education through interdisciplinarity.

Financial decision making is a complex system, which implies a logical choice of available options with considering to alternatives that combine new technologies, including financial information processing (brain), manifesting itself as a network where traditional approaches to financial decision-making are eliminated (making changes difficult with challenges coming from all directions).
\end{abstract}

Keywords: digital financial decision making, neuroplasticity, neurofinance, neural networks.

JEL Classification: D87.

Cite as: Ana Njegovanović. Digital Financial Decision With A View Of Neuroplasticity / Neurofinancy / Neural Networks, Financial Markets, Institutions and Risks, 2(4), 82-91. https://doi.org/10.21272/fmir.2(4).82-91.2018

(C) The Authors, 2018. This article is published with open access at Sumy State University.

\section{Extended Introduction}

Financial decision making is a complex system, which implies a logical choice of available options with considering to alternatives by combining new technologies (the major impact of digital technologiesdigitization of financial products and services and the consequent need to strengthen digital financial literacy, which has become an important component of a global program of policy-making) processing the information (brain) manifesting itself as a network where traditional approaches to financial decision-making are being deleted (making changes difficult with challenges coming from all directions), since artificial intelligence tools serve as a second set of eyes and ears that can help contextualize financial decisions by providing better information - financial advice. The future of AI allows banks to cross the classic core of banking and become more horizontal players. So AI is a general term that encompasses the different approaches and technologies that are set to "think" as people.

"Digitization refers to the practice of downloading processes, content or objects that are predominantly (or totally) physically or analogously transforming them into (or completely) digital. The effect of digitization of the process in addition to potential improvements in efficiency also indicates flexibility and flexibility" (Fichman R., 2014).

The combination of traditional work and technology with artificial intelligence enables autonomous work in self-regulation systems with high quality and high efficiency that leads to increased production speeds by reducing unit costs. Automation has different aspects of realization manifested by: a) changing the amount of work between man and machine; b) trend towards higher automation (a trend that goes to fully automated man-made factories); c) artificial intelligence is a self-learning system with a series various reactions based on ecological conditions. 
As in most cases, technology plays a major role in evolution as well as in the banking sector. Today's AI relies on feeding millions of data to assist split-second decisions from mortgage prequalifications to credit limit upgrades. This pile of data and contracts for their accession are actually what slows down the banking industry so it almost seems like a symbiotic relationship that should have been. There are two main subcategories AI.

The first AI was applied. This is the most common form of AI. This includes everything from intelligent system trading systems to automotive driving.

Generalized AI is less common because it is more difficult to create it. Ideally, generalized AI could manage all sorts of different tasks, just like humans. Although these AIs are not common, many researchers have advanced in the general AI area, this subdivision led to the development of machine learning.

$\mathrm{AI}$ and machine learning - strength lies in the powerful ability to handle and solve complex issues. But there is still a need for cognition and institutional buy-in.

In practice, $\mathrm{AI}$ is a precision tool to use carefully to achieve specific goals. Implementation requires reflection and vision together with understanding of technical challenges. However, the existence of limitations through the lack of understanding of the implications of artificial intelligence in decision-making, the company will not be ready to leap into machine learning in a systematic manner (namely, artificial intelligence must be aligned with the goals, organizations must be data-centric and seek strategic partnerships ).

Fast technological advances in digitization in data, analytics are shaped by a business landscape, supercharging performance that enables new business innovations and new forms of competition to emerge. The technology itself continues to evolve, bringing new advances in robotics, analytics and artificial intelligence (AI), particularly in machine learning, representing the step of changing technical possibilities that could have profound implications for business, the economy, the society, and the labor market.

Digital finance creates the third wave of transformations in financial functions globally. The first wave was managed by an ERP system that linked the company in new ways. The second was offshoring / outsourcing aimed at reducing financial costs. Current digital finance has a potential impact on the function of finance in an even bigger way (Anders Liu-Lindberg, Head of Global Finance PMO, A.P.). Summarized, Digital Finance is the third wave of transformation, enabling improved business results. While the fourth wave is a business partnership as a performance accelerator for coming to the future.

Scientists and innovators have focused their work on the implications, artificial intelligence constructions. The birth of the Big Data movement enabled storage and analysis of the infinite amount of data. Today we come to the era of Deep Learning, which deals with the use of artificial neural networks (ANNs) to facilitate multi-layered learning. This is part of machine learning based on how data is displayed, instead of task-based algorithms. Deep learning has led the way to revolutionizing analytics and enabling practical AI applications.

Neural networks inspired by human brains explore the nature of intelligence from a computer perspective and provide new opportunities for achieving the goal of human intelligence. Artificial neural networks revitalize virtually all decision-making processes in financial assets and the investment area. Leading financial companies around the world use neural networks in solving tasks that require discovery of data samples that avoid conventional analytical methods. Namely, the ability of neural networks lies in their ability to detect nonlinear relationships in the input data set without the premise of knowledge in relation to inputs and outputs. So, the Neural Network is a set of algorithms that try to identify core relationships in a set of data through a process that mimics the way the human brain operates. Neural networks can be adapted to change input data so that the network generates the best possible result without the need to redesign output criteria. The concept of neural networks quickly gains popularity in the area of trade system development.

Incorporating multiple brain areas that coordinate each other indicate how brain decision making (neuroscience research) is being done. Each area of the brain plays a unique role in decision-making, and each of them complement each other to accomplish the task of deciding. Basal ganglia (BG) play a central role in selecting action and reinforcement learning (Mink and Thach, 1993; Mink, 1996; Redgrave et al., 1999). BG contains a set of subcortical cores located in the central brain around the thalamus. The main nucleus of BG contains striatum, internal globus pallidus (GPi), subthalamic nucleus (STN), outer globus pallidus (GPe), substantia nigra pars reticulata (SNr), substantia nigra pars compacta (SNC) and ventral tegmental area (VTA) (Alexander and Crutcher, 1990; Lanciego et al., 2012). 


\section{The Financial Decision-Making Theory}

The theory of financial decision-making is the field of science with a long tradition (reaches hundreds of years). "Decision making theory is an interdisciplinary approach to determine how decisions are made considering to unknown variables and an uncertain framework for decision-making. Decision-making theory links psychology, statistics, philosophy and mathematics to analyze the decision-making process. Decision making theory is closely related to game theory and is studied in the context of understanding activities and decisions that support activities such as auctioning, evolution and marketing "(Investopedia). Discussions on a rational model range from neoclassical economists (Adam Smith or Max Weber) given the rational behavior of participants who maximize utility - homo oeconomicus. Pascala and de Fermata demonstrate probability calculations as Bernoulli laid the foundation for risk science by examining random events. Further development is linked to von Neumann / Morgenster's economic behavior in a rational and mathematical approach. So decision making follows maximizing utility. Today's view of decision theory is manifested through interdisciplinary science (economics, psychology, sociology, philosophy, mathematics, computing, and statistics) with different approaches (Buchanan L. and O'Connell A., 2006). The most popular theory is the theory of games and economic behavior (von Neumann J. and Morgenstern O., 1944). The theory of von Neumann / Morgenstern explains the rational behavior of market participants (either consumers or entrepreneurs). The wide range of mathematical approaches and models of rational theories were developed on the basis of the von Neumann / Morgenstern theory. By the end of the 1940s, Simon talked about the theory of bounded rationality, which implies a certain influence on human attitudes rather than pure rational decisions (Simon H.A., 1997). Psychological science shows that theory of behavior in economics is popular because human behavior is part of organizational action. In the 1970s, Kahneman / Tversky developed a prospect theory. It should also be pointed out to Reinhard Selten who has contributed to the field of behavioral decisionmaking.

Digitalization refers to the practice of taking processes, content or objects that are predominantly (or completely) physically or analogically and transform them primarily (or completely) digitally. The effect of digitization of the process, in addition to potential improvements in efficiency, is that the processes are more flexible and flexible "(Fichman R., 2014) The new era of digitalisation shows a new business world with a change of the labor market and the division of labor.The automation of our world is underway and under strong (Brynjolfsson E. and McAfee A., 2014) The true quantum leap is linguistic automation and its transformation into a massive step for the industry. At the moment, the speed of development, ie the trend of "Industry 4.0" with full automation of production flow (Zelinski P. 2016) or "artificial intelligence" is increased with robotization, making autonomous decisions and developing self-awareness and selfmaintenance (Lee J. 2014).

The effects of digitalisation will completely change the way of doing business and making decisions. Flexibility and transformability are the key attitudes of successful organizations in the future and point them to the way of digitization (Bauer W., 2015). Digitization will have an impact on the user's structure and behavior, increase business efficiency, including the supply chain, and ultimately change the whole business model. (Westerman G., 2014). It is important to understand the logic of digitization and achieve four levels of transformation. These four levels must be within the reach of decision-makers (BDI, 2015).

Kahneman and Tversky have contributed to the development of a behavioral economy. The collection of their scientific contribution and analysis was published in the book "Reflection, Fast and Slow" (Kahneman D., 2011). Describing the theory of decision-making with a strong psychological view, the decision becomes more emotional than rational. Depending on the activated system in mind; Kahneman called System 1 and System 2. "System 1 works automatically and quickly, with little or no effort and no sense for voluntary control" (Kahneman D., 2011). Examples: response $2+2=$ ?; Drive to the idle road, point to the source of sudden sound. "System 2 focuses attention on the tense mental activities that it requires, including complex calculations. System 2 operations are often associated with subjective agency experience, choice, and concentration." Examples are to tell someone your mobile number or fill out a form. The human structure is based on the use of system 1, only if necessary, system 2 is activated. (Kahneman D., 2011.

This concept of System 1 and System 2 sets the foundations for human behavioral decision making, which absolutely abstains from a rational decision-making perspective. The fact is that many decisions have elements of risk of loss and the possibility of gaining a decision on gambling or rejection. By focusing on the aversion of losing (Kahnemann D. and Tversky A., 1974), people avoid losses, while there is a huge opportunity to gain this special opportunity. As a result, people deny this possibility and it is a controversial rational choice, 
with pure probability calculation. On the other hand, "optimistic bias" means that chances of success are overestimated. Risks are underestimated or are not part of decision-making (Kahneman D., 2011).

Nakon procesa, potrebno je napraviti maksimalnu korisnost za odluku. Glavno je pitanje, ako se u organizaciji provede taj striktni proces. Kao H.A. Simon objašnjava, "sve odluke su pitanje kompromisa". U organizaciji s različitim interesima članova, pitanje maksimalne korisnosti problema odlučivanja mora biti ispitano. U organizaciji nikada nije savršeno postignuto postizanje ciljeva. Okruženje organizacije ograničava alternative i maksimalnu korisnost (Simon H.A., 1997). Ovaj suprotan pogled na racionalni proces odlučivanja postavlja pitanje kako se proces odlučivanja u organizacijama doista ostvaruje. Jesu li organizacije jednako racionalne kao i očekivane ili emocionalno pogođene koje utječu na odluke. Utjecaj ponašanja u organizacijama mora se poštivati, a rezultat se temelji na tom postavljanju (March J. \& Simon H.A., 1993).

\section{Digital Technology Bridging Neurosenance}

Digital technology hampers funding in several ways, from blockage to artificial intelligence. Those who implement technology smartly will probably get a competitive advantage, says analyst Scott Rottmann from Genpaca (professional services firm with key office son New Delhy, Palo Alto, Hyderabad, Bengaluru, London, Kolkata and New York). (http://www.digitaljournal.com/business/q-a-how-digital-technology-isdisrupting-finance/article/531752\#ixzz5ZIFHmsM5). Digital technology has damaged finances in several ways. Financing is being developed to include not only traditional financial reporting that relies more on historical information and trends, but also influences financial data to inform the planned activities of the future.

This evolution in finance has helped to: lead sales expectations and revenue planning; generate opportunities for market growth; and focus on targeting strategies and acquiring customers. Data becomes much larger strategic resources for companies, and financial organizations can use digital technology to synthesize information and smarter and faster business decisions for competitive advantage (http://www.digitaljournal.com/business/q-a-how-digital-technology-is-disrupting-

finance/article/531752\#ixzz5ZIG6dM2B ) Digital technologies - such as robotic process automation, machine learning and artificial intelligence - also allow financial departments to improve the efficiency and accuracy of financial and accounting activities, improve compliance efforts, stimulate predictive modeling, and identify market opportunities. Automation helps relieve financial staff of taking additional activities such as recognizing new potential revenues.

From an organization perspective, it is crucial to design and implement digital technologies that can be effectively integrated into existing systems, process and workforce to fully achieve the best return on investment (http://www.digitaljournal.com/business/q-a-how-digital-technology-is-disruptingfinance/article/531752\#ixzz5ZIGcjxQC $)$.

Financial forecasting includes an overview of past and current conditions for predicting the financial future of an organization. This allows companies to closely monitor their carriers and revenue costs and plan to improve the strategy to increase growth projections and address potential barriers (for example, supply chain disturbances, market fluctuations, change of regulations, customer expectations change). Forecasting is especially important for public companies that have to disclose their economic health with shareholders (http://www.digitaljournal.com/business/q-a-how-digital-technology-is-disruptingfinance/article/531752\#ixzz5ZIH8sJ4c ).

The company's financial prediction in 2019 goes in the direction of artificial intelligence solutions so the Genpact prediction showed that machine learning can be used to improve the accuracy of the financial forecast (http://www.digitaljournal.com/business/q-a-artificial-intelligence-assists-with-financial-

forecasting/article/531754\#ixzz5ZIHu3EU0 ). Forecasting is a key step in the business cycle, enabling companies to track finances and plan ahead strategies to boost projected growth and address potential barriers to investors' expectations, geopolitical instability, and overall market fluctuations.

Artificial Intelligence can help in the business process; for example, creating a proper data pipeline using a combination of traditional metrics and non-traditional metrics; analyzing financial and non-financial assets, revealing business data from other data.

Financial forecasting with AI is an emerging area. Key considerations when choosing a solution is the cloudbased platform technology that is modular for easy integration of multiple digital technologies and existing systems. The flexible architecture delivered with the mature interface of software applications provides the 
best results and gives companies the ability to easily complete the operations and the speed of its digital transformation (http://www.digitaljournal.com/business/q-a-artificial-intelligence-assists-with-financialforecasting/article/531754\#ixzz5ZIJE0sbG ).

So, digital technologies are becoming a promising source of solutions to many of the current challenges the population faces by providing innovative ways of monitoring and improving health in the world.

Digital technology bridging neuroscience: virtual reality for brain disorders, speech technology and language therapy, brain neurotehnologics, optical neurobiology and video game-the future of medicine.

Progress in technology and neuroscience methodology appears at a pace and measures are needed to track field movements. Six areas have been identified: cognitive psychology and functional image, targeted delivery of neuropharmacological agents for operative - non-medically indicated purposes, multimodal fusion of neural images and physiological data, new types of average values in fMRI, aggregation of data and translation of meta-analysis and networks default modes.

Multimedia digital technologies reflect neural processes and capacities and their proliferation introduces new learning opportunities. Brain function is all that involves thought, learning, and memory. Although it would be great to categorize and divide the process, neurosis has revealed something that most teachers already know: this is not the way the brain works.

The brain is a triad organ consisting of a motor function (lower / reptilian brain), one for emotion and memory (mammal / limb brain) and one for thinking and thinking (neocortex or brain for thinking). These three different areas of the brain do not function isolated; they work together.

Neuroscience has shown that learning is a result of a holistic approach that triggers the triad brain instead of one part. For educators, this means integrating learning experiences that use a solid research of how brain learning, and neuroscience applications can help with this approach.

\section{Neuroplasticity Of The Market And Financial Decision}

One of the most interesting aspects of the brain is its ability to adapt and change. The term neuroplasticity refers to changes in neural connections, pathways and networks as a result of maturation and development, sensory deprivation, injury, disease, dysfunction and learning. Neuroplasticity is a process that occurs at all levels of nerve pathways and throughout life.

Markets have a plastic sign; they can change form and shape and stay that way afterwards. Traders have always caused this change to succeed in their marketing strategies and efforts. Plasticity, which has so far been considered in marketing, market sociology and evolutionary economics, has the potential to make financial decisions, especially with regard to its role in brain training for sound financial decisions. Implications - The theoretical approach can be embedded in delivering an alternative presentation of the knowledge process associated with financial decisions. A practical approach can be used to improve the practical aspects of the financial decision making process.

Markets are aligned in the sense that they are also created and maintained through sets of interrelated procedures. Markets are socio-materials in the sense that practitioners who create and maintain them include interactions between material heterogeneous entities. Markets organize an economical exchange of meaning that the market can only be recognized as such if economic exchanges are learned (multiples), that does not mean that all market exchanges have to be economized; no economy of exchange is likely to be important in many, if not most, markets (see eg Granovetter, 1985; Spillman 1999).

Thus, markets can be shaped, in varying degrees, in terms of their shapes and functions, and are capable of retaining such changes in their various properties even after the molding steps. Plasticity is a dual construct; this requires fluidity, defined as the ability to form, and stability defined as the ability to retain the form. The plasticity of the market dynamises the socially constructed market value. Expressions such as "dynamics", "development", "and" evolution "are more inclined to the process of market change than the characteristic markets that enable market dynamics. Constructs such as" change "and" fluidity "allow the critical aspect of market dynamics or its double character (Kjellberg et al., 2012), however, plasticity is more appropriate because: everyday use and the etymology of the fracture is related (Rich, 1988), so plasticity is a more appropriate metaphor for a dual ability to take and hold the form. two important consequences of the plastic character of the market as defined above. We can conclude that the ability to retain the shape of it is possible 
for markets to form other subjects, for example, that affect the shape of a particular exchangeable object, in a mode of specific economic exchange, or on the characteristics of replacement assets.

Markets are so performative in the wider sense of the word (Law and Urry, 2004). And the ability to take forms allows the markets to simultaneously come several times to the market. As the participants enable their "market", the markets are multiplied in overlapping versions (Kjellberg and Helgesson, 2006). Human decision-making processes can be contingents in such a way that there may be at least one other alternative that is not impossible but is not necessary for realization (Lehmann-Waffenschmidt, 2010). In such contingent environments characterized by complexity and unpredictability of evolution, favors plasticity (Baldus, 2006). Plasticity is defined as the characterization of a material that changes its shape as a result of the applied force and retains a new form after removing the applied force (Lubliner, 2013). Plasticity in the market context implies that they are "always in the making, subject to multiple changes in efforts and thus taking on more forms" (Nenonen et al., 2014). Increase in portfolio investment led to an increase in occupation and understanding of investor behavior (two schools) rationalists and rhetoricalists. Rationalists assume rational choice, while behaviorists assume that human behavior is the basis of financial decision-making (Sapra and Zak, 2008).

Whenever we are faced with the situation in which we have to decide between the choices made, this leads us to the integration of economics from neuroscience or neuroeconomy as a scientific discipline that helps understanding decisions by decoding the role of different regions of the brain in deciding and bridging the gap between rationalist and behaviorist (Sapra and Zak, 2008). ). This integrated understanding marked the emergence of neurophysiology as a new discipline, trying to correlate the brain process with investment behavior and defining emotions as the key to financial decision-making (Kalra Sahi, 2012).

\section{Neural Networks / Neurofinancial Decision}

The brain is the most complicated machine, neurons are the house of the human brain. It helps our brain to learn, adapt and apply knowledge. The human brain has neurons that help in adaptiveness, learning abilities, and solving any tasks / problems. Unlike the human brain, computer scientists have traced the way to computers that can quickly resolve perceptual problems. This is called "Machine Learning" and therefore the ANN model appeared. Artificial neural networks are nothing but biologically inspired computer models that consist of processing elements (neurons) and links between them, as well as algorithms for training and recall. Thus, neural networks are a kind of computer system that is designed to classify data like our brain. For example, a neural network can look at images, recognize elements in them, and classify them according to what they show.

These networks use the information they have access to in order to determine them. Data does not allow them to be perfectly precise, but can make decisions based on what is most likely to be right.

Most importantly, these systems include a feedback loop for "learning". The machine can find out if its decisions were correct and then change its approach to make it better the next time. processing elements (neurons) and links between them, as well as algorithms for training and recall.

The artificial neural network consists of artificial neurons or processing elements and is organized into three interconnected layers: an entrance, hidden, which may contain more than one layer and outlet. So artificial neural networks use different layers of mathematical processing to ensure the information they feed. Typically, the artificial neuron network has tens of millions of artificial neurons - called units - arranged in a series of layers. The input layer receives various forms of information from the outside world. These are the data that the network wants to process or find out. From the input unit, the data passes through one or more hidden units. The task of the hidden plant is to transform the input into something that the output unit can use.

Computing information processing techniques in basal ganglia has been developed in recent years. Thus, Kenji Doya and colleagues explored biological learning mechanisms and related to computer modeling (Daw and Doya, 2006, Doya, 2007). Joel et al. showed similarity between ventral striatum and cortical function, as well as the similarities between dorsal striatum and the function of complications (Joel et al., 2002). To describe the environment in the real world, the Actor-Critic model was proposed. This method simulated continuous time difference (TD) learning by spiking neurons (Frémaux et al., 2013). However, the gradient removal method used to update weight in the learning process differs from the biological brain learning mechanism. 
Experimental evidence suggests that the decision-making mechanism contains a direct path, an indirect path, and a hyperdirectional pathway. The BG's ( basal ganglia ) detailed operating mechanism is currently believed to be the next. Direct action sends a "Go" signal to facilitate the response to a particular action, while the action on the indirect path sends the signal "Do not Go" to counteract a particular action. Striatum contains two subclasses: "Go" and "No Go" cells. The "Go" cell directly inhibits GPi and has a disinhibiting effect on the thalamus, thereby facilitating a reaction to a particular activity. The "No Go" station on the indirect path first inhibits GPe, then GPe inhibits GPi. So, the "No Go" station has the opposite effect on GPi, suppressing the response to the action in the wake. The hyperdirectional path from STN directly exacerbates GPi (Alexander et al., 1986; Alexander and Crutcher, 1990; Percheron and Filion, 1991)

But from the basal ganglionic system perhaps inspiration is not sufficient because of lack of coordination with the broader areas of the cortex (Alexander et al., 1986) and thalamus (Silkis, 2000, Utter and Basso, 2008). OFC ( orbitofrontal cortex ) represents both a positive and a negative reward from two separate sub-areas, the medial OFC (OFC) and the lateral OFC (OFC) (Elliott et al., 2000; O'Doherty et al., 2001). OFC also has bias on BG by maintaining a contextual reward in the work memory (Tremblay and Schultz, 1999). Inspired by this mechanism, the method of relative reward in Zhao et al. (2017). However, they are only a mathematical computer model without the support of biological realistic neuronal and neural networks (SNN).

The path to Neurofinancing is a relatively new area of research that seeks to understand financial decision making combining insights from psychology and neuroscience with finance theories. Through behavioral experiments, neurofinancials are studying how we estimate information about financial uncertainties, uncertain, time-limited, risky and strategic nature, and how financial decisions affect emotions, psychological prejudice, stress and individual differences (such as gender, genes, neuroanatomy and personality) . In addition, he studies how the brain processes financial information and how individual decisions appear within it. Thus, by combining experiments with computer models, neurofinancing aims to provide an alternative explanation for the apparent failure of classical funding theories.

The term neurofinance was used by David Edwards (2004), who empathize the new science by analyzing financial markets using neurotechnology in the behavioral scenario. According to Rocha et al. (2013) of the first study were directed to behavior by Gehring and Willoughby (2002) using electroencephalography (EEG) for brain activity analysis associated with financial decision-making in the monetary cube task. The study found that "a negative polar event associated with brain potential, probably the generated middle frontal area in or near the front cingular cortex, was greater in amplitude when financial choice resulted in loss when it resulted in getting" (Armando Freitas da Rocha, Vieito and Rocha, 2013a, p 9)

Although the concepts of neurofinancing are very widespread in academic circles, it is noticeable that some researchers use the term as a key word in studies that do not use neuroscience tools, which may confuse new research in this area. Neuroscience is an interdisciplinary science that has several disciplines that may or may not have a more direct relationship with financial problems. The relevant area for finance is cognitive neuroscience. "Cognitive neuroscience deals with more complex mental abilities, most commonly typical to man, such as language, self-consciousness, memory, and others, and can also be termed neuropsychology (Lent, 2010, p.6). These limitations between neuroscience are not very clear and sometimes need unification to the second level for a deeper insight into financial issues. Neurofinance is an interdisciplinary wrist that evaluates the nervous system and brain as a unit of analysis, but not considering that investors are irrational but look at brain regions that are used at the time when it comes to making financial decisions by using the equipment of some cerebral or physiological maps.This has emerged as a combined effort of neuroscience and finance to better understand the dynamics of decision making creation, seeking a type of knowledge that includes the neural mechanisms involved and the risk of analysis (Armando F. da Rocha, 2013; Armando Freitas da Rocha \& Rocha, 2011), pp are concerned about the approach of financial decision-making in neurofinancing and their reflection in the brain and may be like a bridge between psychology, neurology and behavior of investors (Sapra \& Zak, 2008). , neurofinancing "by means of brain imaging technology, experimentally identifies specific neuronal substrates associated with acquisition and processing of information related to financial decision" (Gippel, 2013). There are several methods available for brain research including neurological equipment such as Functional Magnetic Resonance (fMRI), Electroencephalyography (EEG), Magnetoencephalography (Meg), Transcranial Magnetic Stimulation (TMS) Positron Emission Tomography (PET) as well as psychophysical equipment such as electrocardiogram (ECG or ECG), galvanic skin response (GSR) and eye monitoring. Figure 1 shows an example of this brain image representing fMRIoutput from Kuhnen and Knutson (2005) showing different brain regions affecting gain versus loss and relative market value. 
How does our brain work the same way as to whether this is a good precondition for financial tasks? As Professor C. Rieck (Finance Professor at the University of Frankfurt) points out, the computer is a useful addition to artificial intelligence as well. It is explained by the approach that a man has a small storage capacity and computing to show in detail large numbers.

How do we handle financial decisions?

It results in a compression data mechanism. So, mathematically, we do not work with the original numerical values, but with their algorithms. This is smart in most natural situations. However, when it comes to financial issues, it can often lead us in the wrong direction when it comes to financial problems. There are many such artifacts.

For example, losses are systematically different from profits. Not only are the losses worse but the risks. It catches us panic when we see short-term fluctuations and we do not realize we're losing money.

All these are the consequences of building a central brain treatment unit, optimized for all but financial decisions. These errors are well documented in behavioral finance research, which implies understanding how the brain processes information.

Artificial Intelligence in Counseling does not have the task of predicting the future and thus achieving better portfolio performance. But their job is to make financial decisions so that we can better live with them. So the real task of investment robots will be to protect themselves from themselves. Just like a good human resource manager. Except that the robot is not subject to typical errors in the human brain. Because the robot is not a multipurpose weapon, but optimized for that purpose. That is why he is a much better companion in wealth than can ever be.

\section{Concluded on Digital Decision Making}

How to Define Financial Decision Making? Managers and business owners need to take account of financial reasons with each major decision they make for their business. Whether the decision to include capital expansion, asset protection or acquisition of capital equipment or merger with another firm solid financial analysis will ensure that the decision is made with the best available information. How do we make strategic decisions in a digital-complex environment? . Making strategic decisions at a strategic level is considered the most important thing that is becoming more and more difficult. The way we choose is the way of "choosing (logical) choices from available options." Decision-making can be difficult because of the selection process, probability and risk weighing. What we know is coming from a more diverse source - these parallel phenomena have numerous supporters of marked changes. New organizations act by trusting the information they gain, as well as the expertise and experience of their management teams. With digital expansions, they make faster, lower risk decisions such as the result of threats to traditional companies across the various industrial sectors. Therefore, significant investment in technology, which must, of course, be aligned with moving force, leads to changes in business models, structures and processes.

If we sum up the digital environment, we can conclude briefly that digitization and globalization lead to comoditization and threat to established business models. Intangible assets-such as brands, customer relationships, intellectual property, and human capital-have become the main driving force in business. This requires adapting your own business models or developing new ones. This achievement is a way of making quality decisions as a key and insight into value creation data, and thus become a quick successor to organizational success.

As a key area of financial innovation in this decade, digital finance (fintech) has natural advantages in financial inclusion in light of its features such as sharing, convenience, low cost and easy access. Digital financial inclusion aims to use digital technologies to improve financial inclusion and attract more attention from many countries. However, there were no high-level guidelines in this area. Defining digital finance as financial services delivered through digital infrastructure, including mobile and Internet connections, indicates low cash consumption compared to the traditional banking sector. Mobile Phones, PCs or POS Cards connect individuals and businesses with digitized national payment infrastructure, enabling flawless transaction across the board.

Artificial Intelligence (AI) as a research domain for scientists - the technique for accepting human intelligence in the machine. The machines are effectively trained to perform and carry out a series of human operations. Today, AI has widespread applications to solve problems in various sectors, whether they are technology and robotics, academics, industry, defense, healthcare or financial and banking areas. In this context, in order to 
create AI, a lot of algorithms such as neural networks, tree decisions, random forest and intelligence are gradually gaining an emphasis in research laboratories for the financial industry.

Namely, AI growth is increasingly felt in the areas of financial management. As we move from prediction and preselection of the analytic era into the space of cognitive analytics, the role of algorithm algorithms such as neural networks, tree decision, random forest, genetic algorithms, intelligence, and others will gradually become more prominent with the era of automation with smart technologies that trigger sensors (Kar 2016; Chakraborty, 2017; Gupta et al., 2018). In the days to come, the way these technologies contribute to the value of a company is something where a lot of research efforts are being carried out on a continuous basis. Data science specialists are continually focusing on promising applications that would change the way AI gives interesting insights from the huge amount of data obtained in the financial services industry.

Conducted research indicates:

$>$ "The Artificial Neural Network (ANN), an AI-based tool, has tremendous potential for solving financial problems. ANN or Neural networks are computer programs that simulate the problem with an effective algorithm. ANN is a well-established and proven technique that deals with prediction, clustering and classification of new data. These aspects find their use in the finance sector, where potential applications include bankruptcy risk assessment, identification of arbitration options, and technical and fundamental analysis (Hawley, 1990). Certain financial problems are effectively solved using ANN Tools AI. In recent times, the variation of ANN has become popular because deep learning and developed neural networks have begun to develop.

$>$ The complex financial operation is broken into simple multiple sub-tasks where the mutual relations between these sub-tasks are even more critical. The ANN manages these situations more effectively in the corporate financial environment. ANN is used to model these sub-tasks so they are trained to work as static or dynamic entities in accordance with changes in the financial organization of a company. Real-time examples include prediction of the company's financial behavior. Here input parameters consist of economic and user data, while the output parameter is expected to purchase or pay the buyer behavior. Analyzing the previous customer history, ANN is trained. This is useful for developing a system for performing bad debt analysis, cyclical expansion and contract accounting, cash management, capital investment assessment, asset and personnel risk management, and forecasting costs and availability of credit based on the company's financial performance.

$>$ In the future, it is believed that AI supports financial sectors in maximizing resources, reducing risk factors and being more profitable in trading, investing, banking, lending. Artificial Intelligence provides a platform for banks and financial companies to save time and money by using algorithms to gain better insight and prediction about the company's sales performance and provide better customer service delivery.

AI helps to apply rules and decisions on inventory-based inventory trading (Chakraborty, 2016). Corporate corporations implemented such algorithms based on AI trained data based on human emotions and behaviors, drawn from social media analysis (Rathore, 2017) and collecting statistical data. In Hong Kong, stock trading is carried out autonomously using AI-based algorithms, while Nomura Securities in Japan depends on AIbased robotic traders to increase profits in stock transactions (Aegon Life / 2018).

\section{References}

1. Alexander G. E., Crutcher M. D. (1990). Functional architecture of basal ganglia cicuits: neural substrates of parallel processing. Trends Neurosci. 13, 266-271. 10.1016/0166-2236(90)90107-L

2. Alexander G. E., DeLong M. R., Strick P. L. (1986). Parallel organization of functionally segregated circuits linking basal ganglia and cortex. Ann. Rev. Neurosci. 9, 357-381. 10.1146/annurev.ne.09.030186.002041

3. Brybijolfosson E. and McAfee A., 2014. The Second Machine Age. New York: W.W. Norton and Company

4. Chakraborty, P. S., Majumder, G., \& Sarkar, B. (2006). Constraint resource management and production related decision - A case study. Journal of the Institution of Engineers (India), Part PR: Production Engineering Division, 86(MAR.), 48-53.

5. Daw N. D., Doya K. (2006). The computational neurobiology of learning and reward. Curr. Opin. Neurobiol. 16, 199-204. 10.1016/j.conb.2006.03.006

6. Doya K. (2007). Reinforcement learning: computational theory and biological mechanisms. HFSP J.1, 30-40. 10.2976/1.2732246/10.2976/1 
7. Elliott R., Dolan R. J., , and Frith C. D. (2000). Dissociable functions in the medial and lateral orbitofrontal cortex: evidence from human neuroimaging studies. Cerebral cortex, 10, 308-317. $10.1093 /$ cercor/10.3.308

8. Gadde L. E. \& L. G. Mattsson (1987) : «Stability and Change in Network Relationship »; International Journal of Research in Marketing; Vol.4; pp.29-41.

9. Granovetter, Mark. 1985. Economic Action and Social Structure: The Problem of Embeddedness: American Journal of Sociology $91:$ 481-510.

10. Hans Kjellberg et al., Market futures / future markets: Research directions int he study of market. 2012. Marketing Theory 12 (2): 219-223.

11. Himanshu rathore, An inventory Model for Deteriorating Item with Reliability Consideration and Trade Credit 2014. Pakistan Journal of Statistics and Operation Research 10 ( 3 ).

12. Kahneman D. and Tversky A., 1974. Judgment Under Uncertainty: Heuristics and Biases. Science, New Series, Vol. 184.

13. Lanciego J. L., Luquin N., Obeso J. A. (2012). Functional neuroanatomy of the basal ganglia. Cold Spring Harb. Perspect. Med. 2:a009621. 10.1101/cshperspect.a009621.

14. Law, John and Urry, John ( 2004 ) Enacting the social. Economy and Society, 33(3) pp. 390-410.

15. Lubliner, 2013. Issues in Structural and Materials Engineering, Q Ashton Acton, PhD General Editor

16. Mink J. W. (1996). The basal ganglia: focused selection and inhibition of competing motor programs. Prog. Neurobiol. 50, 381-425. 10.1016/S0301-0082(96)00042-1

17. Mink J. W., Thach W. T. (1993). Basal ganglia intrinsic circuits and their role in behavior. Front. Neurosci. 3, 950-957. 10.1016/0959-4388(93)90167-W.

18. Neumann von, J. \& Morgenstern O., 1944. Theory of Games and Economic Behaviour. Princeton: University Press

19. O'Doherty J., Kringelbach M. L., Rolls E. T., Hornak J., Andrews C. (2001). Abstract reward and punishment representations in the human orbitofrontal cortex. Nat. Neurosci. 4, 95-102. 10.1038/82959

20. Percheron G., Filion M. (1991). Parallel processing in the basal ganglia: up to a point. Trends Neurosci. 14, 55-56. 10.1016/0166-2236(91)90020-U

21. Rich Charron et al.," Optimum Junction Hybrid push/pull production systems" International Journal of Production Research. International Journal of Physical Distribution and Logistics Managment, 28(1), 1843, 1997.

22. Rocha, A. F., Vieito, J. P. and Rocha Ff. T. ( 2013 b) Neurofinance: How Do We Make Financial Decisions. SSRN Electronic Journal 10-11.

23. Silkis I. (2000). The cortico-basal ganglia-thalamocortical circuit with synaptic plasticity. i. modification rules for excitatory and inhibitory synapses in the striatum. Biosystems 57, 187-196. 10.1016/S03032647(00)00134-9

24. Spillman, Lyn. 1999. "Enriching Exchange: Cultural Dimensions of Markets.” American Journal of Economics and Sociology 58: 1047-71.

25. Tremblay L., Schultz W. (1999). Relative reward preference in primate orbitofrontal cortex. Nature398, 704-708. 10.1038/19525.

26. Utter A. A., Basso M. A. (2008). The basal ganglia: an overview of circuits and function. Neurosci. Biobehav. Rev. 32, 333-342. 10.1016/j.neubiorev.2006.11.003

27. Zelinski P., 02/2016. Where 4.0. Might Go . (Online ) http://www. mmsoline.com. ( Accessed 10.04.2016).

28. Zhao F., Zeng Y., Wang G., Bai J., Xu B. (2017). A brain-inspired decision making model based on topdown biasing of prefrontal cortex to basal ganglia and its application in autonomous uav explorations. Cogn. Comput. 6, 1-11. 10.1007/s12559-017-9511-3

29. http://www.digitaljournal.com/business/q-a-how-digital-technology-is-disruptingfinance/article/531752\#ixzz5ZIFHmsM5

30. http://www.digitaljournal.com/business/q-a-how-digital-technology-is-disruptingfinance/article/531752\#ixzz5ZIG6dM2B

31. http://www.digitaljournal.com/business/q-a-how-digital-technology-is-disruptingfinance/article/531752\#ixzz5ZIGcjxQC

32. http://www.digitaljournal.com/business/q-a-how-digital-technology-is-disruptingfinance/article/531752\#ixzz5ZIH8sJ4c

33. http://www.digitaljournal.com/business/q-a-artificial-intelligence-assists-with-financialforecasting/article/531754\#ixzz5ZIHu3EU0 